\title{
Profil Meaning of Life Siswa Budaya Karo
}

\author{
Herda Fitri Br Ginting ${ }^{1}$, Nur Hidayah ${ }^{1}$, Blasius Boli Lasan ${ }^{1}$ \\ ${ }^{1}$ Bimbingan dan Konseling-Universitas Negeri Malang
}

\section{INFO ARTIKEL}

\section{Riwayat Artikel:}

Diterima: 07-12-2018

Disetujui: 19-02-2019

\section{Kata kunci:}

meaning of life;

Karo culture;

budaya Karo

\author{
Alamat Korespondensi: \\ Herda Fitri Br Ginting \\ Bimbingan dan Konseling \\ Universitas Negeri Malang \\ Jalan Semarang 5 Malang \\ E-mail: herdafitri782@gmail.com
}

\section{ABSTRAK}

Abstract: Meaning of life is values that are used as life guidelines, are important and valuable, sourced from comes from creative values, experential values, and attitudional values. Meaning of life involves all aspects of experience in an individual's life, involving every aspect of value, character, relationships with others, and also the way of life. Culture has a major role in the formation and fulfillment of the profile of the meaning of life of the Karo people. The study of the profile of the meaning of life of Karo culture was carried out through content analysis of the results of interviews with the Karo regional language teachers. Meaning of life Karo culture has eight values compiled according to three sources of value meaning of life.

\begin{abstract}
Abstrak: Meaning of life adalah nilai-nilai yang dijadikan pedoman hidup, bersifat penting, berharga, serta bersumber dari creative values, experential values, dan attitudional values. Meaning of life melibatkan seluruh aspek pengalaman dalam hidup individu, melibatkan setiap aspek nilai, karakter, hubungan dengan orang lain, dan cara hidup. Budaya memiliki peran utama dalam pembentukan dan pemenuhan profil. meaning of life masyarakat Karo. Pengkajian profil meaning of life budaya Karo dilakukan melalui analisis isi terhadap hasil wawancara terhadap guru bahasa daerah Karo. Meaning of life budaya Karo memiliki delapan nilai yang disusun sesuai tiga sumber nilai meaning of life.
\end{abstract}

Meaning of life merupakan bagaimana individu memaknai kehidupannya, mulai dari bagaimana individu memiliki harapan dalam hidupnya hingga memiliki alasan atas segala sesuatu yang dilakukan dalam mempertahankan kehidupannya yang bermakna (Frankl, 2012). Seseorang yang telah menemukan meaning of life tentunya akan dapat memaknai, memiliki tujuan dan bertindak tepat atas keberadaan dirinya di dunia ini (Frankl, 2014; Ho, Cheung, \& Cheung, 2010). Meaning of life sebuah konsep digagas oleh Viktor E. Frankl. (Frankl, 2014) "Meaning of life" didapatkan tiga jenis nilai yaitu creative values, experiential values, dan attitudinal values. Creative values ialah bekerja dan berkarya serta melaksanakan tugas dengan tanggungjawab penuh dan terlibat pada pekerjaan atau kepemimpinan. Experiential values ialah nilai-nilai penghayatan mencoba meyakini dan menghayati berbagai nilai yang ada terdapat di kehidupan, seperti kebenaran, keindahan, kasih sayang, kebajikan, dan keimanan. Attitudinal values ialah nilai-nilai yang menjadi respon berupa bagaimanapun sikap individu tunjukkan terhadap takdir atau situasi yang dihadapi, misalnya respon berupa sikap peserta didik pada saat menghadapi kegagalan ujian.

Manusia dalam proses memiliki meaning of life, bukan dengan menciptakannya, namun manusia perlu untuk menemukannya dan manusia tidak akan menemukannya jika tidak mencarinya (Pattakos, 2008). Individu memiliki kemungkinan kesalahan dalam mengevaluasi terhadap kondisi diri, arah hidup, nilai-nilai lingkungan dan sebagian yang ada dan berinteraksi dalam kehidupan mereka (Landau, 2011). Creative values, experiential values, dan attitudinal values tidak lepas dari adanya evaluasi atas kondisi diri dan lingkungan. Meaning of life memiliki unsur objektivitas dalam proses evaluasi tersebut menjadikan individu dapat menemukan dan memiliki meaning of life untuk dirinya.

Kehadiran meaning of life dalam kehidupan seseorang mengacu pada sejauh mana seseorang dapat memahami, mengerti dan melihat pentingnya meaning of life bagi kehidupan mereka, disertai dengan tingkatan terhadap pencapaian atas tujuan kehidupan mereka (Steger, Oishi, \& Kashdan, 2009). Konsep meaning of life individu dipengaruhi oleh komponen subjektif yang berasal dari diri individu melalui pengalaman hidup, pandangan dan penilaian oleh pribadi mereka sendiri, dan komponen objektif yang merupakan nilai-nilai dan moral yang berkembang yaitu nilai-nilai budaya yang ada di lingkungan mereka (Hanafi, Hidayah, \& Mappiare, 2018; Wolf, 2010; Zhang et al., 2016). 
Kehadiran meaning of life dalam kehidupan individu tidak dapat dipisahkan kaitannya dengan bagaimana orang memandang diri mereka dan pengaruh budaya mereka. Steger (Steger, Kawabata, Shimai, \& Otake, 2008) semakin memperkuat adanya pengaruh sebagai budaya dalam penentuan sumber nilai, harapan dan kebutuhan pada diri masyarakatnya. Berdasarkan paparan yang telah disampaikan, maka makna setiap budaya akan memiliki sebuah bentuk meaning of life nya sendiri (Steger et al., 2008). Hal ini dikarenakan nilai-nilai budaya akan menjadi kebenaran intersubjektif meaning of life yang harus dipenuhi masyarakatnya. Kondisi ini berlaku pada budaya-budaya yang ada di Indonesia, salah satunya budaya Karo. Budaya Karo merupakan budaya yang dimiliki oleh suku Karo di kabupaten Karo (Prihartanti, 2008; Singarimbun, 2015). Suku Karo atau juga disebut suku Batak Karo sebagai salah satu suku terbesar di Sumatera Utara memiliki kearifan lokal yang masih terjaga (Viner, 2017). Hal ini ditunjukkan dengan adanya wilayah wisata adat Karo di Berastagi, Lau Kawar, Kabanjahe dan masih banyak lagi di desa-desa yang masih memiliki rumah adat. Suku Karo memiliki ciri khas bahwa setiap individu pasti memiliki marga (family) (Singarimbun, 2015; Tarigan, 2016). Marga di Karo ada lima, yaitu Karo-karo, Ginting, Tarigan, Sembiring, dan Perangin-angin (Tarigan, 2008).

Adanya desa wisata adat Karo merupakan salah satu indikasi bahwa budaya Karo masih dilestarikan, dijaga, dan dipertahankan oleh masyarakat suku Karo (Tarigan, 2016). Kondisi ini menunjukkan masih terdapat kesepakatan masyarakat atas nilai-nilai budaya Karo yang berlaku. Dengan kata lain, kebenaran intersubjektif atas nilai budaya Karo menjadi unsur objektivitas bagi anggota masyarakat Karo dalam menemukan dan memenuhi profil meaning of life nya. Objektivitas ini berlaku kepada seluruh elemen masyarakat Karo termasuk para remaja Karo yang tengah menempuh pendidikan di sekolah.

Peserta didik dengan latar budaya Karo tentu akan bertemu dengan budaya lain dalam kehidupannya di lingkungan sekolah dan masyarakat. Pihak sekolah, termasuk konselor memiliki peran membantu peserta didik memiliki meaning of life budaya Karo, sehingga dapat mempertahankan dan melestarikan budaya Karo yang dimilikinya pada saat berinteraksi dengan budaya dari luar Karo. Oleh karena itu, pengkajian profil atas objektivitas dari meaning of life budaya Karo akan menjadi sumber rujukan konselor/guru bimbingan dan konseling dalam mengarahkan bagaimana peserta didik dengan budaya Karo dapat memiliki dan memenuhi meaning of life budaya Karo-nya. Hal ini dikarenakan meaning of life termasuk budaya Karo yang memengaruhi kehidupan siswa dalam aspek pribadi-sosial dan aspek belajar dan karir. Keempat aspek tersebut merupakan ranah profesionalitas konselor dalam membantu siswa untuk dapat berkembang mandiri dan optimal (Lasan, 2014). Meskipun meaning of life juga terbentuk atas unsur subjektivitas peserta didik, kerangka objektivitas meaning of life budaya Karo dapat menjadi tolak ukur pencapaian meaning of life peserta didik berlatar budaya Karo.

\section{METODE}

Metode yang digunakan menggunakan metode deskriptif dengan menggunakan teknik analisis isi (content analysis). Analisis isi dilakukan terhadap data hasil wawancara peneliti terhadap guru Bahasa daerah Karo di Desa Gajah, Kecamatan Simpang Empat, Kabupaten Karo menjadi data dalam teknik analisis isi. Instrumen utama dalam penelitian ini ialah peneliti sendiri. Peneliti juga didukung oleh instrumen sekunder dari informan, literatur, catatan penelitian, dan analisis data dilakukan setelah seluruh data terkumpul.

\section{HASIL}

Hasil analisis isi pada hasil wawancara terhadap guru Bahasa daerah Karo di Desa Gajah memberikan delapan gambaran nilai budaya Karo. Kedelapan gambaran nilai budaya Karo tersebut antara lain.

Pertama, "Nese - Nese Sitik Bagi Remang Erpagi-Pagi”. Artinya suatu pekerjaan akan selesai jika dikerjakan sedikit demi sedikit atau pekerjaan yang dilakukan secara gotong royong. Masyarakat juga sering mengandaikan persoalan kehidupan dengan nese-nese sitik bagi remang erpagi-pagi, setiap persoalan kehidupan sedikit demi sedikit akan terselesaikan.

Kedua, "Keri Gia Lau Pola, Gelah kitangna I Sangketken". Masyarakat memiliki prinsip bekerja sesuai dengan peran dan tugas-tugasnya.

Ketiga, "Mejuah - Juah." Mejuah juah adalah suatu salam suku Karo, namun tidak hanya salam biasa saja, karena didalamnya terkandung sebuah makna yang menjadikan orang Karo berada didalam kejuah-juahen (damai sejahtera, bahagia dan sehat). Mejuah-juah secara umum yang artinya sehat lahir bathin.

Keempat, "Merdang-Merdem". Mungkin suku-suku yang terdapat di Sumatera Utara, hanya Orang Karo yang memiliki budaya kerja tahun (Pesta Tahun)/Merdang Merdem. Merdang Merdem dilaksanakan setiap tahun, seperti layaknya perayaan tahun baru/hari raya. Setelah masuknya Agama baru Kristen dan Islam, pelaksanaan merdang merdem telah bergeser nilai-nilai religinya dan telah mendapatkan penekanan sebagai hari raya untuk silaturahmi keluarga untuk dapat berkunjung setiap tahun. Pelaksanaan merdang merdem memiliki tahapan-tahapan kegiatan sebagai berikut.

Hari pertama, cikor-kor. Cikor-kor adalah tahap pertama untuk melaksanakan merdang-merdem di suatu daerah ataupun wilayah. Cikor-kor itu berarti mencari-cari beberapa serangga di dalam tanah dan dibawah pohon dan dijadikan menjadi lauk makanan di hari pertama. Hari kedua, cikarung. Dihari kedua masih mencari hewan kecil yaitu bernama kurung. Kurung itu ada di sawah atau di ladang, dan dijadikan lauk makanan oleh pelaksana merdang merdem. Hari ketiga, ndurung. Ndurung itu mencari nurung. Nurung itu sejenis ikan mas dan jika ada yang menangkap lele, belut, kaperas atau ikan yang lainnya maka hari itu memakan yang sudah di ndurung. Hari keempat, manten. Manten sama dengan motong dimana hari keempat ini adalah hari persiapan menuju puncaknya merdang merdem. Di manten memotong hewan-hewan yang cukup besar 
dan berat untuk lauk, seperti kerbau, lembi, sapi, babi. Hari kelima, matana. Dihari kelima ini adalah puncak acara dimana kerabat dari segala penjuru mengunjungi kerabat masing-masing. Kerabat yang berkunjung ke kampung itu akan disediakan makanan yang sangat beragam, mulai dari makanan hari pertama sampai makanan hari keempat. Di setiap desa pada umumnya memiliki sebuah aula yang besar yang sering disebut dengan Los. Los yang sudah dihiasi oleh masyarakat untuk menjamu tamu-tamu yang dating pada hari itu. Aturan pada saat hari kelima yaitu berkunjung ke setiap rumah dan di setiap rumah harus dan wajib makan. Hari keenam, nimpa. Di hari keenam ini masyarakat membuat makanan khas Karo yaitu cimpa. Cimpa ini adalah hidangan setelah selesai makan dan terbuat dari tepung terigu, gula merah, dan kelapa parut. Di kampung lain ada juga namanya ngerires/lemang. Makanan cimpa dan rires/lemang lumayan makanan yang tahan lama dan cocok untuk oleh oleh bagi tamu ketika pulang. Hari ketujuh, rebu. Di hari ketujuh ini adalah hari terakhir dari acara merdang-merdem. Di hari ketujuh tidak ada aktivitas ataupun kegiatan di kampung karena para tamu sudah kembali ke kampungnya maisng-masing. Rebu sama dengan berdiam diri di rumah karena pergi ke sawah dilarang. Di hari terakhir ini dapat disimpulkan hari istirahat warga kampung untuk enam hari yang sudah sangat letih dan memberikan waktu istirahat untuk menyambut besok hari untuk beraktivitas seperti hari hari yang sering dilakukan.

Kelima, "Sikuning kuningen radu megersing, siageng agengen radu mbiring". Artinya bahwa kita saling kerjasama untuk mendapatkan hasil yang baik. Berat sama dipikul, ringan sama dengan dijinjing.

Keenam, "Merga Silima, Rakut Sitelu, Tutur Siwaluh,”. Masyarakat Etnis Karo sebagai masyarakat yang terikat dalam kekeluargaan. Setiap orang Karo mempunyai dasar hubungan, yaitu Merga silima, tutur si waluh, rakut sitelu. Setiap orang Karo memiliki ataupun memiliki dasar hubungan. Rakut Sitelu (tiga ikatan), suatu ungkapan menggambarkan satu sistem dengan tiga unsur yang erat hubungannya satu sama lain atau unsur kelengkapan hidup dalam suatu keluarga luas. Dengan kata lain, falsafah itu hanya berfungsi jika ada ketiga unsurnya. Rakut sitelu sama dengan pengertian dalihan natolu pada masyarakat Batak yang ada di Sumatera Utara. Rakut sitelu adalah istilah kekerabatan yang mengikat sesame anggota masyarakat memalui perkawinan dan kelahiran, dan dasar dari pembagian suatu kelompok adat istiadat di Karo. Makna didalam rakut sitelu adalah sebagai pedoman hidup, penjelas hubungan kekerabatan, pengharmonisan antar umat beragama, dan sarana penyelesaian konflik. Implementasi nilai-nilai rakut sitelu di dalam keluarga adalah perbedaan panggilan kepada setiap orang, penyelenggara upacara adat, serta penentuan sikap saat berinteraksi dengan orang lain. Tujuan dari pemberian merga ialah sebagai salah satu tanggung jawab terhadap masyarakat Karo, dan sebagai dasar hubungan kekeluargaan kepada masyarakat Karo.

Ketujuh, “Adi La Beluh Ertutur, Labo Siat Ku Japa Pe”. Jika tidak dapat bertutur, maka tidak ada tempat harga dirinya/tempat di Karo. Ertutur itu tata cara untuk tanya-jawab sisilah diri sendiri dan keberadaan nya di adat istiadat Karo. Tutur dapat dilihat tingkatannya dalam bebera jenis yaitu Bapak, Ibu, Paman, Bibi/Istri Paman, Seninan, Sembuyak, Turang, Impal, Bere-bere, Anak, Adik, Abang, Kakek, Nenek, dan masih banyak lagi. Budaya ertutur mayarakat Karo menurut (Tarigan, 2008) ada enam lapis. Budaya ertutur merupakan cara pengungkapan identitas selaku warga Karo. Marga/Beru, Bere-bere, Binuang, Kempu, Kampah, Soler. Marga/beru diwariskan oleh Ayah, Bere-bere diwariskan dari Ibu, Binuang diwariskan oleh bere-bere Ayah, Kempu diwariskan oleh bere-bere Ibu, Kampah diwariskan dari beru nenek dari Ayah, Soler diwariskan dari beru nenek dari Ibu.

Kedelapan, "Mela Mulih Adi La Rulih”. Artinya malu pulang tanpa membawa hasil atau jika kita pergi bekerja/belajar. Suatu slogan yang menarik di setiap sekolah-sekolah di Tanah Karo. Slogan Mela Mulih Adi La Rulih mampu memotivasi siswa untuk dapat sukses di dalam kehidupan. Kedelapan gambaran nilai budaya Karo tersebut selanjutnya dikaji dalam kerangka meaning of life yang terdiri atas creative values, experiential values dan attitudinal value. Pengkajian meaning of life dalam budaya Karo memberikan paparan nilai-nilai budaya Karo yang memang menjadi kerangka profil meaning of life budaya Karo. Nilai-nilai budaya Karo dalam kerangka meaning of life budaya Karo tersaji pada tabel 1.

Tabel 1. Nilai Budaya Karo dalam Kerangka Meaning of Life

\begin{tabular}{|c|c|c|}
\hline Fenomena Budaya Suku Karo & $\begin{array}{l}\text { Nilai Budaya } \\
\text { Suku Karo }\end{array}$ & $\begin{array}{l}\text { Meaning Of Life } \\
\text { (Viktor Frankl) }\end{array}$ \\
\hline $\begin{array}{l}\text { Masyarakat suku Karo memiliki falsafah "nese nese sitik bagi remang erpagi-pagi” } \\
\text { mengerjakan sesuatu secara bersama sama, sedikit demi sedikit pekerjaan itu akan selesai } \\
\text { dan memiliki suatu hasil. }\end{array}$ & Gotong royong & $\begin{array}{l}\text { Creative values/ Nilai } \\
\text { Kreatif }\end{array}$ \\
\hline $\begin{array}{l}\text { Masyarakat suku Karo memiliki falsafah "keri gia lau pola, gelah kitangna I sangketken” } \\
\text { masyarakat memiliki prinsip bekerja sesuai dengan peran dan tugasnya. }\end{array}$ & Bekerja & \\
\hline $\begin{array}{l}\text { Mejuah juah bukan hanya sekedar salam bagi suku Karo, tapi juga sebuah prinsip menjaga } \\
\text { kedamaian dengan diri sendiri, alam semesta, orang sekitar bahkan orang orang diluar } \\
\text { suku Karo. }\end{array}$ & Kedamaian & $\begin{array}{l}\text { Experiential values/ } \\
\text { Nilai Penghayatan }\end{array}$ \\
\hline $\begin{array}{l}\text { Masyarakat suku Karo menyakini acara "merdang-merdem" mampu memberikan ucapan } \\
\text { syukur kepada sang pencipta karena berkatnya berlimpah setiap saat. }\end{array}$ & Keagamaan/religious & \\
\hline
\end{tabular}


Tabel 1. Nilai Budaya Karo dalam Kerangka Meaning of Life (Lanjutan)

\begin{tabular}{|c|c|c|}
\hline Fenomena Budaya Suku Karo & $\begin{array}{l}\text { Nilai Budaya } \\
\text { Suku Karo }\end{array}$ & $\begin{array}{l}\text { Meaning Of Life } \\
\text { (Viktor Frankl) }\end{array}$ \\
\hline $\begin{array}{l}\text { Masyarakat suku Karo menjunjung tinggi "sikuning-kuningen radu megersing, siageng } \\
\text { agengen radu mbiring” yang penting mengerjakannya dengan kebersamaan. }\end{array}$ & Kerjasama & \\
\hline $\begin{array}{l}\text { Masyarakat Karo sangat menjunjung tinggi sistem adat dan memiliki"merga silima, tutur } \\
\text { siwaluh, rakut sitelu” memiliki tali persaudaraan yang kuat. }\end{array}$ & Kekerabatan & $\begin{array}{l}\text { Attitudinal values/ } \\
\text { Nilai Bersikap }\end{array}$ \\
\hline Masyarakat Karo menjaga tata karma, ramah “adi la beluh ertutur, labo siat kujapa pe”. & Kesopansantunan & \\
\hline $\begin{array}{l}\text { Masyarakat karo berusaha mendapatkan/mengerjakan sesuatu supaya memiliki hasil "mela } \\
\text { mulih adi la rulih" }\end{array}$ & Kerja Keras & \\
\hline
\end{tabular}

\section{PEMBAHASAN}

Hasil analisis isi telah memaparkan delapan karakteristik dan nilai budaya masyarakat suku Karo. Kedelapan falsafah atau karakteristik nilai tersebut selanjutnya telah diadopsi pada kerangka bentuk nilai meaning of life. Tabel 1 telah memaparkan bagaimana hasil adopsi tersebut. Nilai-nilai budaya dan karakteristik masyarakat suku Karo menjadi fenomena atas bagian bentuk nilai meaning of life masyarakat Karo. Paparan kedelapan karakteristik dan nilai budaya Karo, tidak serta merta menjadikan adanya delapan nilai dalam adopsi pada kerangka meaning of life. Kedelapan nilai hasil analisis isi atas wawancara terhadap guru budaya Karo dianalisa secara per satu dan secara timbal balik terhadap konsep bentuk nilai meaning of life. Bentuk nilai meaning of life berupa creative values, axperential values, dan attitudinal values dikaji kesesuaian nilainilai budaya dalam karakteristik masyarakatnya.

Meaning of life yang melibatkan seluruh aspek pengalaman dalam hidup individu, tentu akan melibatkan setiap aspek karakter, nilai, hubungan dengan orang lain, dan juga tata cara hidup individu. Dalam hal ini, budaya memiliki peran utama dalam pembentukan, pengarahan, dan pemenuhan meaning of life masyarakatnya. Sehingga, bagaimana masyarakat suku Karo menemukan, membentuk dan memenuhi meaning of life nya, sangat dipengaruhi oleh nilai-nilai yang berkembang pada cara kehidupan budaya Karo. Sistem meaning of life diketahui mengambil dari keyakinan dan sudut pandang budaya, Antara lain karakter sikap, harga diri, kontrol diri dan ketergantungan pada kepekaan dan persepsi kita, hasil penelitian Steger (Steger, 2012).

Fenomena-fenomena budaya Karo, yang memaparkan kebiasaan masyarakat, keyakinan, karakter masyarakat dan nilai budaya Karo merupakan unsur-unsur yang membentuk identitas sosial bagi setiap individu dalam budaya Karo. Terbentuknya identitas sosial bagi masyarakat Karo, tak lepas dari kesepakatan budaya yang akan menjadi kebenaran bagi setiap masyarakat Karo. Kesepakatan ini seperti pendapat Mori \& Hayashi (Mori \& Hayashi, 2006) yang telah dipaparkan bahwa kesepakatan budaya merupakan sebuah kebenaran intersubjektif bagi masyarakat Karo.

Pemenuhan nilai-nilai hasil kesepakatan dalam kebenaran intersubjektif masyarakat Karo tentu akan memberikan sebuah pengakuan identitas sosial bagi setiap anggota masyarakat Karo. Identitas sosial seorang berbudaya Karo tidak hanya dikarenakan individu telah memiliki nilai-nilai budaya Karo. Identitas sosial seorang berbudaya Karo tidak hanya dikarenakan individu memiliki nilai-nilai budaya Karo, namun juga dibuktikan melalui pengakuan dari masyarakat suku Karo lainnya Identitas sosial memiliki keterkaitan dengan meaning of life melalui proses perkembangan identitas melalui hubungan dengan kelompok. Dengan demikian, profil meaning of life individu berlatar budaya Karo sangat bergantung bagaimana individu tersebut memenuhi nilai budaya Karo dan berkehidupan menjalin hubungan dengan masyarakat sekitarnya.

Nilai budaya Karo yang menyiratkan pentingnya hubungan dengan orang lain menunjukkan bahwa budaya Karo termasuk pada budaya kolektivis. Budaya kolektivis cenderung memandang diri individu dalam lingkaran hubungan dnegan orang-orang disekitarnya karena masyarakat sekitar memiliki peran yang penting dalam setiap bagian hidupnya (Kiang \& Fuligni, 2010). Cross, Hardin \& Gercek-Swing (Cross, Hardin, \& Gercek-Swing, 2011) menyatakan bahwa individu dengan budaya kolektivis akan memandang dirinya berkaitan dan berhubungan dengan orang lain. Adanya persepsi akan pentingnya keterlibatan orang lain dalam kehidupan individu, tentu juga akan berpengaruh dalam pembentukan meaning of life. Profil meaning of life budaya Karo memiliki keterkaitan dengan pola hubungan masyarakat Karo.

\section{SIMPULAN}

Meaning of life budaya Karo merupakan kajian analisis isi atas hasil wawancara peneliti terhadap guru Bahasa daerah Karo. Pengkajian meaning of life budaya Karo merupakan bagian dari meaning of life yang dimiliki oleh masyarakat Karo. Meaning of life budaya Karo yang telah dikaji oleh peneliti merupakan profil meaning of life dan unsur objektif yang dimiliki masyarakat Karo yang berasal dari kebenaran intersubjektivitas dan kesepakatan budaya masyakarat Karo.

Delapan nilai budaya Karo yang telah ditemukan peneliti dari hasil wawancara terhadap guru Bahasa daerah Karo dipaparkan dan dikaji dalam kerangka meaning of life budaya Karo. Pengkajian ini merupakan penyesuaian atas setiap nilai budaya Karo dengan tiga nilai yang menjadi sumber nilai meaning of life. Kerangka meaning of life budaya Karo akan membantu masyarakat Karo untuk dapat menemukan meaning of life diterima masyarakat Karo. 
Saran yang disampaikan peneliti bagi konselor adalah profil kerangka meaning of life budaya Karo dapat dijadikan konselor di sekolah dalam membantu peserta didik dengan budaya Karo untuk memenuhi dan meningkatkan meaning of life. Beberapa penelitian telah dilakukan oleh Hidayah (Hidayah, Ramli, \& Hanafi, 2018; Hidayah \& Ramli, 2017; Hidayah, Ramli, \& Hanafi, 2017) yang dapat menjadi rujukan dalam mengembangkan layanan konseling untuk meningkatkan meaning of life siswa di Indonesia. Saran bagi peneliti selanjutnya dapat mengkaji lebih lanjut melalui metode lain terkait penyusunan kerangka meaning of life budaya Karo sehingga dapat menjadi perbandingan dan penyempurnaan kerangka meaning of life budaya Karo. Peneliti selanjutnya juga dapat menggunakan kerangka meaning of life budaya Karo hasil penelitian ini sebagai penelitianpenelitian lanjutan terkait dengan meaning of life budaya Karo.

\section{DAFTAR RUJUKAN}

Cross, S. E., Hardin, E. E., \& Gercek-Swing, B. (2011). The what, how, why, and where of self-construal. Personality and Social Psychology Review, 15(2), 142-179. https://doi.org/10.1177/1088868310373752

Frankl, V. E. (2012). Man's Search for Meaning: An Introduction to Logotherapy (4th Edition). Boston: Beacon Press.

Frankl, V. E. (2014). On the theory and therapy of mental disorders : An introduction to logotherapy and existential analysis. On the Theory and Therapy of Mental Disorders : An Introduction to Logotherapy and Existential Analysis. https://doi.org/10.4324/9780203005897

Hanafi, H., Hidayah, N., \& Mappiare, A. (2018). Adopsi Nilai Budaya Osing Dalam Kerangka Meaning of Life. Jurnal Pendidikan: Teori, Penelitian, dan Pengembangan, 3(9), 1237-1243.

Hidayah, N., \& Ramli, M. (2017). Need of Cognitive-Behavior Counseling Model Based on Local Wisdom to Improve Meaning of Life of Madurese Culture Junior High School Students. In Advances in Social Science, Education and Humanities Research (Vol. 128, pp. 301-307). Atlantis Press.

Hidayah, N., Ramli, M., \& Hanafi, H. (2017). Urgency Cognitive-Behavioral Counseling Based on Local Wisdom For Junior High School Counselor In East Java. In Advances in Social Science, Education and Humanities Research (Vol. 118, pp. 923-928). Atlantis Press.

Hidayah, N., Ramli, M., \& Hanafi, H. (2018). East Java Modeling Techniques to Improve Student Meaning of Life. In Advances in Social Science, Education and Humanities Research (Vol. 269, pp. 181-185). Atlantis Press.

Ho, M. Y., Cheung, F. M., \& Cheung, S. F. (2010). The Role of Meaning in Life and Optimism in Promoting Well-Being. Personality and Individual Differences, 48(5), 658-663. https://doi.org/10.1016/j.paid.2010.01.008

Kiang, L., \& Fuligni, A. J. (2010). Meaning in Life as a Mediator of Ethnic Identity and Adjustment Among Adolescents from Latin, Asian, and European American Backgrounds. Journal of Youth and Adolescence, 39(11), 1253-1264. https://doi.org/10.1007/s10964-009-9475-z

Landau, I. (2011). Immorality and the meaning of life. Journal of Value Inquiry, 45(3), 309-317. https://doi.org/10.1007/s10790-011-9293-X

Lasan, B. B. (2014). Konselor Sekolah: Tinjauan dan Upaya Profesionalisasi. Malang: Elang Mas.

Mori, J., \& Hayashi, M. (2006). The Achievement of Intersubjectivity Through Embodied Completions: A Study of Interactions Between First and Second Language Speakers. Applied Linguistics, 27(2), 195-219. https://doi.org/10.1093/applin/aml014

Pattakos, A. (2008). Prisoners of Our Thoughts: Viktor Frankl's Principles for Discovering Meaning in Life and Work. San Francisco, California: Berrett-Koehler Publishers, Inc.

Prihartanti, N. (2008). Mencapai Kebahagiaan Bersama Dalam Masyarakat Majemuk. Jurnal Psikologi Indonesia, 2008(01), 73-79.

Singarimbun, M. (2015). Kinship, Descent, and Alliance among the Karo Batak. Berkeley: University of California Press.

Steger, M. A., Oishi, S., \& Kashdan, T. B. (2009). Meaning in Life Across the Life Span: Levels and Correlates of Meaning in Life from Emerging Adulthood to Older Adulthood. Journal of Positive Psychology, 4(1), 43-52. https://doi.org/10.1080/17439760802303127

Steger, M. F. (2012). Making Meaning in Life. Psychological Inquiry, 23(4), 381-385. https://doi.org/10.1080/1047840X.2012.720832

Steger, M. F., Kawabata, Y., Shimai, S., \& Otake, K. (2008). The Meaningful Life in Japan and the United States: Levels and correlates of meaning in life. Journal of Research in Personality, 42(3), 660-678. https://doi.org/10.1016/j.jrp.2007.09.003

Tarigan, S. (2008). Dinamika Orang Karo, Budaya dan Modernisme. Medan: Balai Adat Budaya Karo Indonesia.

Tarigan, S. (2016). Mengenal Rasa, Karsa, dan Karya Kebudayaan Karo. Medan: Balai Adat Budaya Karo Indonesia.

Viner, A. C. (2017). The Changing Batak. Journal of the Malaysian Brach of Royal Asiatic, 1, 80-100.

Wolf, S. (2010). The Meaning of Life and Why It Matters. Handbook of Positive Psychology. NJ: Princeton University Press.

Zhang, H., Sang, Z., Chan, D. K. S., Teng, F., Liu, M., Yu, S., \& Tian, Y. (2016). Sources of Meaning in Life Among Chinese University Students. Journal of Happiness Studies, 17(4), 1473-1492. https://doi.org/10.1007/s10902-015-9653-5 